\title{
PENGARUH STRATEGI COPING TERHADAP TINGKAT STRES PADA CAREGIVER INFORMAL YANG MERAWAT PENDERITA SKIZOFRENIA DI POLI RAWAT JALAN RUMAH SAKIT JIWA DR.SOEHARTO HEERDJAN JAKARTA BARAT.
}

\author{
Rahmalia Dewi Fitriani ${ }^{1)}$, Ria Maria Theresa ${ }^{2)}$, Citra Ayu Aprilia ${ }^{3)}$ \\ ${ }^{1)}$ Program Studi Profesi Dokter, Fakultas KedokteranUPN Veteran Jakarta \\ email:rahmaliadewiif@gmail.com \\ ${ }^{2)}$ Departemen Psikiatri, Fakultas Kedokteran UPN Veteran Jakarta \\ email:ria.maria@upnvj.ac.id \\ ${ }^{3)}$ Departemen Farmakologi - Farmasi, Fakultas KedokteranUPN Veteran Jakarta \\ email: citra.ayuaprilia@upnvj.ac.id
}

Corresponding author: dr. Citra Ayu Aprilia, M.Kes (citra.ayuaprilia@upnvj.ac.id / HP:08122090545)

\begin{abstract}
Limited psychiatric healthcare and being chronic, schizophrenia makes schizophrenia patient's family hold important role as informal caregivers. Objective of this research was to know demography characteristic distribution and impact of coping strategy against schizophrenia informal caregiver's stress level at Dr. Soeharto Heerdjan psychiatric hospital, out-patient unit. Coping stress very depends on individual characteristics. This research was set to observational analytic with cross sectional design. Subjects of research were 32 caregivers, adapting research instrument CSI-SF 32 items and PSS-14 items. The result of research, majority of the caregivers is a woman and middle adulthood age. Most of caregivers goes to work and tend more than 4 years with nursing time more than 6 hours /day. There was impact of coping strategy against stress level of schizophrenia informal caregivers $(p=0,006)$. Most used coping strategy was adaptive coping with medium stress level. Long term could increase caregivers burden, so that it can trigger stress and could lower caregivers mental health status and could affect the treatment quality for schizophrenia patient. Writer recommended psychiatric healthcare to put psychological awareness and psycho-education intervention of stress management for caregivers.

Keyword :Coping Strategy,Informal Caregivers, Schizophrenia, Stress Level,

PENDAHULUAN

World Health Organization melaporkan terdapat 21 juta penderita skizofrenia di dunia. Prevalensi skizofrenia di Indonesia pada tahun 2013 sebanyak $1,7 \%$ danpada tahun 2018 sebanyak $7,1 \%$ angka ini cukup meningkat signifikan dibandingkan pada tahun 2013 sebelumnya (Badan Penelitian dan Pengembangan Kesehatan, 2018). Di Indonesia, hampir $70 \%$ mereka yang dirawat di bagian psikiatri adalah karena Skizofrenia baik rawat jalan maupun rawat inap (Zahnia \& Sumekar, 2016, hlm. 161).

Gangguan skizofrenia menyebabkan perubahan kepribadian dan ketidak sesuaian sosial sehingga penderita membutuhkan bantuan orang lain, terutama anggota keluarga sebagai caregiver (Nainggolan \& Hidajat, 2013, hlm.22). Keluarga yang secara mandiri memberikan pendampingan dan perawatan dinamakan caregiver informal (Solichach \& Fahrunnisa, 2017, hlm.2-3).

Beberapa masalah yang dialami oleh caregiver dengan pasien gangguan jiwa berat yaitu meningkatnya stres dan kecemasan keluarga karena beban
\end{abstract}


perawatan (Mubin\& Andriani, 2013, hlm.300). Caregiver pasien skizofrenia juga rentan terkena stres hingga depresi. Kurnilla (2016) yang menyatakan bahwa caregiver yang mengalami stres dalam merawat pasien gangguan jiwa sebanyak 78,3\% dari total 23 responden. Upaya yang digunakan untuk menangani stres tersebut adalah dengan menggunakan strategi coping (Rofiah, 2015, hlm. 5-7). Setiap individu memiliki tingkat toleransi stres, cara coping, dan akses terhadap dukungan sosial yang berbeda sehingga tingkat stres setiap individu bervariasi mulai dari ringan sampai dengan berat. Strategi coping yang digunakan setiap caregiver bervariasi dan dapat bersifat adaptif maupun maladaptif.

Berbagai studi telah meneliti stres dan penggunaan strategi coping yang khususnya menilai coping yang berorientasi masalah atau emosi pada caregiver dengan menggunakan alat ukur yang berbeda-beda. Namun masih jarang yang membahas tentang strategi coping dengan menggunakan alat ukur yang menilai apakah coping yang telah digunakan adaptif (efektif) atau maladaptif (tidak efektif) pada caregiver skizofrenia dan pengaruhnya terhadap tingkat stres. Karena terbatasnya informasi tersebut peneliti tertarik untuk meneliti tentang pengaruh strategi coping terhadap tingkat stress pada caregiver informal skizofrenia.

\section{METODE PENELITIAN}

Jenis penelitian menggunakan studi analitik obeservasional yang bertujuan membandingkan variabel pada subjek penelitian melalui sampel yang diteliti dengan desain penelitian yang digunakan adalah analitik obeservasional. Rancangan ini dimaksudkan untuk melihat pengaruh variabel independen (strategi coping) terhadap variabel dependen (tingkat stres) yang dilakukan satu kali dan satu waktu. Penelitian di Poli Rawat Jalan Rumah Sakit Jiwa Dr.Soeharto
Heerdjan, Jakarta Barat pada bulan Juni 2019.

Jumlah sampel yang digunakan dalam penelitan ini berjumlah32 responden yang diambil dengan teknik non probability sampling dengan metode purposive sampling.

Sampel pada penelitian ini adalah caregiver skizofrenia di poli rawat jalan yang mendampingi pasien skizofrenia di Rumah Sakit Jiwa Dr.Soeharto Heerdjan dan memenuhi kriteria inklusi data seperti, merupakan caregiver informal (keluarga, saudara, teman), usia 20-65 tahun, merawat satu pasien yang sama dengan diagnosis skizofrenia. Data tersebut diperoleh dari penyebaran kuesioner oleh peneliti.

Variabel dalam penelitian ini terdiri dari variabel independen dan dependen. Variabel independenya itu strategi copings edangkan variabel dependent tingkat stres. Analisis data yang dilakukan pada penelitian terdiri dari analisis univariat dan bivariat. Analisis penelitian ini menggunakan uji ChiSquare.

\section{HASIL DAN PEMBAHASAN}

Responden dari penelitian ini berjumlah 32 responden terdiri dari 21 caregiver adalah wanita $(65,6 \%)$. Usia caregiver terbanyak pada usia dewasa madya (41-60 tahun) yaitu 19 orang $(59,4 \%)$. Wanita pada usia dewasa madya menjadi mayoritas caregiver karena memiliki waktu yang cukup luang dan mengalami perubahan hormon menjelang menopause sehingga cenderung stres, mudah lelah, dan mengalami suasana hati yang berubahubah (Mubin\&Andriani, 2013, hlm.301). Pendidikan terakhir terbanyak pada caregiver yaitu pada jenjang SMA/SMK dengan jumlah 21 orang (65,6\%). Penelitian Yazici, et.al., (2016, hlm.99) menyatakan bahwa semakin tinggi tingkat edukasi maka beban yang dirasakan caregiver semakin rendah.

Sebanyak 29 orang $(90,6 \%)$ sudah menikah. Kegiatan yang paling banyak dilakukan caregiver yaitu bekerja dengan jumlah 22 orang $(68,8 \%)$. 
Berdasarkan penelitian Kate, et.al., (2013, hlm.386) pekerjaan berdampak terhadap tingkat beban stres caregiver. Hal tersebut dapat disebabkan karena bertambahnya peran dan tugas caregiver sedangkan kemampuan coping yang dimiliki tetap sehingga terjadi ketidakseimbangan.

Relasi terbanyak yang dimiliki caregiver dan pasien adalah sebagai orang tua dengan jumlah 16 orang $(50,0 \%)$. Lama merawat terbanyak yaitu selama lebih dari 4 tahun dengan jumlah 14 orang $(43,8)$ dengan durasi merawat paling banyak adalah > 6 jam. Usia pasien didapatkan hasil terbanyak yaitu dewasa awal (20 - 40 tahun) dengan jumlah 25 orang $(78,1 \%)$ dan jenis kelamin pasien terbanyak adalah pria dengan jumlah 25 orang $(78,1 \%)$.Usia pasien skizofrenia didominasi rentang usia 20-40 tahun (dewasa awal) yakni 25 orang dan berjenis kelamin pria sebanyak 25 orang. Hal ini sesuai dengan karakteristik skizofrenia yaitu banyak terjadi pada pria dengan onset dewasa awal (Kaplan et.al., 2010, hlm.147-148).

Tabel 1. Distribusi Karakteristik Demografik Responden

\begin{tabular}{|c|c|c|}
\hline NO. & $\begin{array}{c}\text { Karakteristik } \\
\text { Demografi }\end{array}$ & $\begin{array}{r}\text { Frekuen } \\
(\mathbf{n}=\mathbf{3 2}\end{array}$ \\
\hline \multirow[t]{3}{*}{1.} & JenisKelamin & \\
\hline & Pria & 11 \\
\hline & Wanita & 21 \\
\hline \multirow{5}{*}{2.} & Usia & \\
\hline & $\begin{array}{l}\text { Dewasa Awal } \\
(20-40 \text { tahun })\end{array}$ & 8 \\
\hline & Dewasa & 19 \\
\hline & $\begin{array}{l}\text { Madya (41 - } \\
60 \text { tahun) }\end{array}$ & \\
\hline & $\begin{array}{l}\text { Dewasa Akhir } \\
\text { (> } 60 \text { tahun) }\end{array}$ & 5 \\
\hline
\end{tabular}

3. Pendidikan

$\begin{array}{lc}\text { SD } & 5 \\ \text { SMP } & 2 \\ \text { SMA/SMK } & 21 \\ \text { PT } & 4\end{array}$

4. Status

Pernikahan

Belum

3

4

Menikah

Menikah

5. Status

Pekerjaan

Bekerja

Tidak Bekerja

6. Relasi dengan

Pasien

Orang Tua

Suami

Istri

Anak

Saudara

Kandung

Lain-Lain

7. Lama

Merawat

$<1$ tahun

$1-4$ tahun

$>4$ tahun

8 Durasi

Merawat

3-6 Jam/hari

$>6 \mathrm{Jam} / \mathrm{hari}$

9. UsiaPasien

Dewasa Awal

(20 - 40 tahun)

Dewasa

29

90,6

Madya (41 -

60 tahun)

Dewasa Ak

68,8

10

31,3

hir (> 60

tahun)

$\begin{array}{cc}16 & 50,0 \\ 1 & 3,1 \\ 7 & 21,9 \\ 0 & 0 \\ 6 & 18,8 \\ & \\ 2 & 6,3\end{array}$

10

31,3

$8 \quad 25$

$14 \quad 43,8$

43,8

40,6

$19 \quad 59,4$

$25 \quad 78,1$

$7 \quad 21,9$

0
10. JenisKelamin

(\%)

34,4

65,6

Pria

Wanita

Sumber: Data Primer, 2019
25 Tabel 2 Kategorisasi Strategi Coping Nilai Frekuensi Persentase

$59,4 \quad$ Skor $\quad(\mathbf{n}=\mathbf{3 2}) \quad(\%)$

Coping $\quad(\mathbf{n}=32)$

$\begin{array}{lllll}, 6 & \begin{array}{l}\text { Mal- } \\ \text { adaptif } \\ \text { Adaptif }\end{array} & 115- & 12 & 37,5 \\ & 32- & 20 & 62,5 \\ 114 & & \end{array}$

15,6 Sumber: Data Primer, 2019

6,3 Berdasarkan tabel 2, dari 32

65,6 responden penelitian terdapat 20 orang

$12,5(62,5 \%)$ yang sudah menggunakan coping adaptif dan 12 orang (37,5\%) menggunakan coping maladaptif. 
Tabel 3 Kategorisasi Tingkat Stres

\begin{tabular}{|c|c|c|}
\hline $\begin{array}{l}\text { Nilai } \\
\text { Skor } \\
\text { Stres }\end{array}$ & $\begin{array}{c}\text { Frekuensi } \\
(\mathbf{n}=\mathbf{3 2})\end{array}$ & $\begin{array}{c}\text { Persentase } \\
(\%)\end{array}$ \\
\hline Ringan $0-14$ & 3 & 9,4 \\
\hline Sedang $15-28$ & 20 & 62,5 \\
\hline Tinggi $29-42$ & 9 & 28,1 \\
\hline $\begin{array}{l}\text { Sangat } 43-56 \\
\text { Tinggi }\end{array}$ & 0 & 0 \\
\hline
\end{tabular}

Sumber: Data Primer, 2019

Berdasarkan tabel 3, dari 32 responden penelitian didapatkan hasil sebanyak 20 orang $(62,5 \%)$ mengalami stres sedang dan tidak ada yang mengalami stres sangat tinggi.Namun ada beberapa caregiver yang mengalami stress tinggi.

\begin{tabular}{ccccc}
\multicolumn{5}{c}{ Tabel 4. Pengaruh Strategi Coping } \\
Terhadap Tingkat Stres \\
\begin{tabular}{ccccc} 
Strategi & \multicolumn{2}{c}{ Tingkat Stres } & & \\
Coping & $\begin{array}{c}\text { Sedang } \\
\text { n }(\%)\end{array}$ & $\begin{array}{c}\text { Tingg } \\
\text { i }\end{array}$ & Total & $\begin{array}{c}\text { P- } \\
\text { value } \\
\end{array}$ \\
n (\%)
\end{tabular} & & \\
\hline Mal- & 5 & 7 & 12 & \\
adaptif & 15,6 & 21,9 & 37,5 & \\
Adaptif & 18 & 2 & 20 & 0,006 \\
& 56,3 & 6,3 & 62,5 & \\
Total & 23 & 9 & 32 & \\
& 71,9 & 28,1 & 100 & \\
\hline
\end{tabular}

Sumber: Data Primer, 2019

Dari Tabel 4, diperoleh hasil sebanyak 18 orang $(56,3 \%)$ mengalami stress dengan kategori sedang dan telah menggunakan strategi coping kategori adaptif. Setelah dilakukan penggabungan sel, dilakukan uji alternative yaitu uji fisher dan didapatkan nilai $\mathrm{p}$ valuesebesar 0,006. $(\mathrm{p}=0,006) \quad$ Jika $\mathrm{p}$ value < 0,05 maka hipotesis penelitian diterima, sehingga dapat disimpulkan terdapat hubungan atau pengaruh strategi coping terhadap tingkat stress caregiver.

Sesuai dengan penelitian Darlami et.al., (2016, hlm.39) yaitu adanya relasi strategi coping dengan stres dan Grover et.al., (2015, hlm.5) juga menyatakan bahwa terdapat asosiasi coping terhadap beban, perasaan emosi, dan morbiditas psikologis caregiver pasien skizofrenia.Selama pendampingan pasien skizofrenia, caregiver mengalami stres karena berbagai situasi seperti menghadapi perubahan perilaku pasien, memberikan perawatan rutin dalam jangka waktu lama yang sudah menjadi responsibilitas caregiver sebagai keluarga, frekuensi relaps pasien, dan stigma masyarakat.

Stres merupakan suatu situasi subjektif yang dianggap menekan bagi individu. Faktor lainnya adalah gaya hidup di perkotaan cenderung lebih memicu stres. Berbagai studi juga menyatakan caregiver yang tinggal di perkotaan merasakan beban lebih berat (Kate et.al., 2013, hlm.386). Tingkat stres pada caregiver informal bergantung pada persepsi mereka terhadap situasi stres yang dialami dan kemampuan adaptasi atau coping mereka.

Menurut Afriyeni \& Sartana (2016, hlm.119) karakteristik caregiver salah satu hal yang mempengaruhi seberapa besar beban dan tekanan yang dirasakan caregiver. Didukung penelitian Nainggolan \& Hidajat (2013, hlm.21) yaitu kepribadian caregiver menjadi faktor penting dalam mengevaluasi stressor, menentukan kemampuan adaptif atau pilihan coping yang turut mempengaruhi kesejahteraan psikologis caregiver. Strategi coping adalah suatu proses mengelola tuntutan eksternal atau internal yang dianggap membebani atau melebihi sumber daya individu tersebut (Grover et.al., 2015, hlm.5). Hasil penelitian ini menggambarkan bahwa lebih banyak caregiver informal skizofrenia yang menggunakan coping adaptif. Situasi jangka lama yang dihadapi memungkinkan caregiver skizofrenia dapat menyesuaikan dirinya menghadapi stres walaupun stres tersebut tetap dirasakan dalam tingkat yang berbedabeda dan mayoritas tingkat stres caregiver pada tingkat sedang. Dukungan sosial ikut mendukung strategi copingcaregiver, sesuai dengan teori Solichah\&Fahrunnisa (2017, hlm.1) strategi coping yang digunakan tiap subjek penelitian dipengaruhi oleh 
dukungan sosial. Caregiver menyatakan perubahan yang mereka ciptakan untuk mengatasi stres (strategi coping) dapat mengurangi efek negatif dari stres yang dirasakan dan membuat pendampingan terhadap pasien skizofrenia lebih terasa ringan. Coping yang dilakukan misalnya dukungan dari teman dan keluarga, keyakinan pada Tuhan dan meluangkan waktu untuk relaksasi diri (RileyMcHugh et.al., 2016, hlm.99).

\section{KESIMPULAN}

a Karakteristik demografi caregiver mayoritas wanita $(65,6 \%)$, berusia 41-60 tahun (dewasa madya) (59,4\%), Pendidikan terakhir SMA/SMK $(65,6 \%)$, status menikah (90,6\%), mempunyai pekerjaan $(68,8 \%)$, relasi dengan pasiens ebagian besar adalah orang tua pasien $(50 \%)$, Lama merawat selama >4 tahun (43,8\%), durasi perawatan paling banyak berkisar $>6 \mathrm{jam} / \mathrm{hari}$ sedangkan untuk usia pasien yang dirawat sebagian besar berada pada rentang usia 20-40 tahun (dewasa awal) $(78,1 \%)$ dan berjenis kelamin pria $(78,1 \%)$.

b Sebagian besar Caregiver informal skizofrenia menggunakan strategi coping adaptif.

c Sebagian besar caregiver skizofrenia mengalami stress kategori sedang. Tidak ada yang mengalami stress kategori sangat tinggi, namun ada beberapa yang mengalami stress tinggi dan perlu perhatian khusus.

d Terdapat pengaruh strategi coping terhadap tangka tstres pada caregiver informal skizofrenia di polirawat jalan RSJ Dr.Soeharto Heerdjan.

\section{SARAN}

a. Caregiver sebaiknya berusaha lebih terbuka untuk menyampaikan perasaan dan bercerita tentang masalahnya kepada orang-orang terdekatnya, meluangkan waktu untuk dirinya sendiri, dan membuat to-do list sehingga dapat meringankan beban caregiver. b. Sebaiknya rumah sakit jiwa juga memperhatikan psikologis caregiver dengan memberikan intervensi psikoedukasi untuk manajemen stress dan mengenai gangguan jiwa skizofrenia agar mereka lebih mengerti dalam menghadapi pasien skizofrenia yang mereka damping dan rawat

\section{DAFTAR PUSTAKA}

Afriyeni, N \& Sartana 2016, 'Gambaran Tekanan dan Beban yang Dialamui oleh Keluarga sebagai Caregiver Penderita Psikotik di RSJ Prof. H.B. Sa'Anim Padang', jurnal Ecopsy, vol.3, no.3, hlm.34-51, diakses 5 Maret 2019 https://.unlam.ac.id\%2Fjournal\%F index.phplMw.

Badan Penelitian dan Pengembangan Kesehatan Kementrian Kesehatan RI 2018, Riset Kesehatan Dasar (RISKESDAS), Badanlitbang Kemenkes RI, Jakarta, diakses 12 Oktober 2018

http://www.depkes.go.id/resource s/download/infoterkini/materi_rakorpop_2018/Ha sil\%20Riskesdas\%202018.pdf

Grover, S, Pradyumna, Chakrabarti, S 2015, 'Coping among the caregivers of patients with schizophrenia', Industrial Psychiatry Journal, vol.24, no.1, hlm.5-11, diakses 29 Desember 2018

https://www.ncbi.nlm.nih.gov/pm c/articles/PMC4525432/.

Kaplan HI, Sadock BJ, Grebb JA 2010, Sinopsis Psikiatri Jilid 2, Terjemahan Widjaja Kusuma, Binarupa Aksara, Jakarta

Kate, N, Grover, S, Kulhara, P, Nehra, R 2013, 'Relationship of caregiver burden with coping strategies, social support, psychological morbidity, and quality of life in the caregivers of schizophrenia', Asian Journal of Psychiatry, vol.6, no.5, hlm.380-388, diakses 20 Desember 2018 
https://www.ncbi.nlm.nih.gov/pub med/24011684

Kurnilla, MD 2016, 'Tingkat Stres Pada Caregiver Pasien Gangguan Jiwa Psikotik', Skripsi Program Studi Kedokteran, Universitas Diponegoro, diakses tanggal 18 Maret 2019

http://eprints.undip.ac.id/55450/

Mubin, MF \& Andriani, T 2013, 'Gambaran Tingkat Stres Pada Keluarga Yang Memiliki', Prosiding Konferensi Nasional PPNI Jawa Tengah 2013, hlm. 299-302, diakses tanggal 6 Oktober 2018

https://jurnal.unimus.ac.id/index.p hp/psn12012010/article/view/898

Nainggolan, NJ, \& Hidajat, LL 2013, 'Profil Kepribadian dan Psychological Well-Being Caregiver Skizofrenia', Jurnal Ilmiah Psikologi, vol.6,no.1, hlm.22-42, diakses 18 Februari 2019

http://jurnal.unismabekasi.ac.id/in dex.php/soul/article/view/632

Riley-McHugh, D, Hepburn Brown, C, Lindo, J 2016, 'Schizophrenia: its psychological effects on family caregivers', International Journal of Advanced Nursing Studies, vol.5, no.1, hlm.96-101, diakses 25 Desember 2018

https://www.researchgate.net/publ ication/301247929 Schizophrenia its psychological effects on fa mily caregivers

Rofiah, S 2015, 'Hubungan antara kecerdasan emosi dengan strategi coping pada caregiver formal lansia, Skripsi Program Studi Psikologi, Universitas Negeri Semarang', diakses tanggal 21 November 2018

https://lib.unnes.ac.id/23050/1/15 11411121.pdf

Solichach, M, Fahrunnisa, F 2017, 'Strategi Coping pada Caregiver Penderita Stroke', Jurnal Psikologi Integratif, vol.5, no.1, Hlm.1-10, diakses 27 April 2019 http://ejournal.uin-
suka.ac.id/isoshum/PI/article/view $\underline{1380}$

World Health Organization (WHO) 2018, 'Schizophrenia ', diakses 2 Februari 2019

https://www.who.int/newsroom/factsheets/detail/schizophrenia

Zahnia, S \& Sumekar, DW 2016, 'Kajian Epidemiologis Skizofrenia', Medical Journal Of Lampung University, vol.5, no.4, hlm.160-166, diakses 15 September 2018 http://juke.kedokteran.unila.ac.id/i ndex.php/majority/article/view/90 $\underline{4 / 812}$ 